\title{
Entrevista al Profesor Ramón Félix Caropresi
}

Por Victoria Baraldi (1)

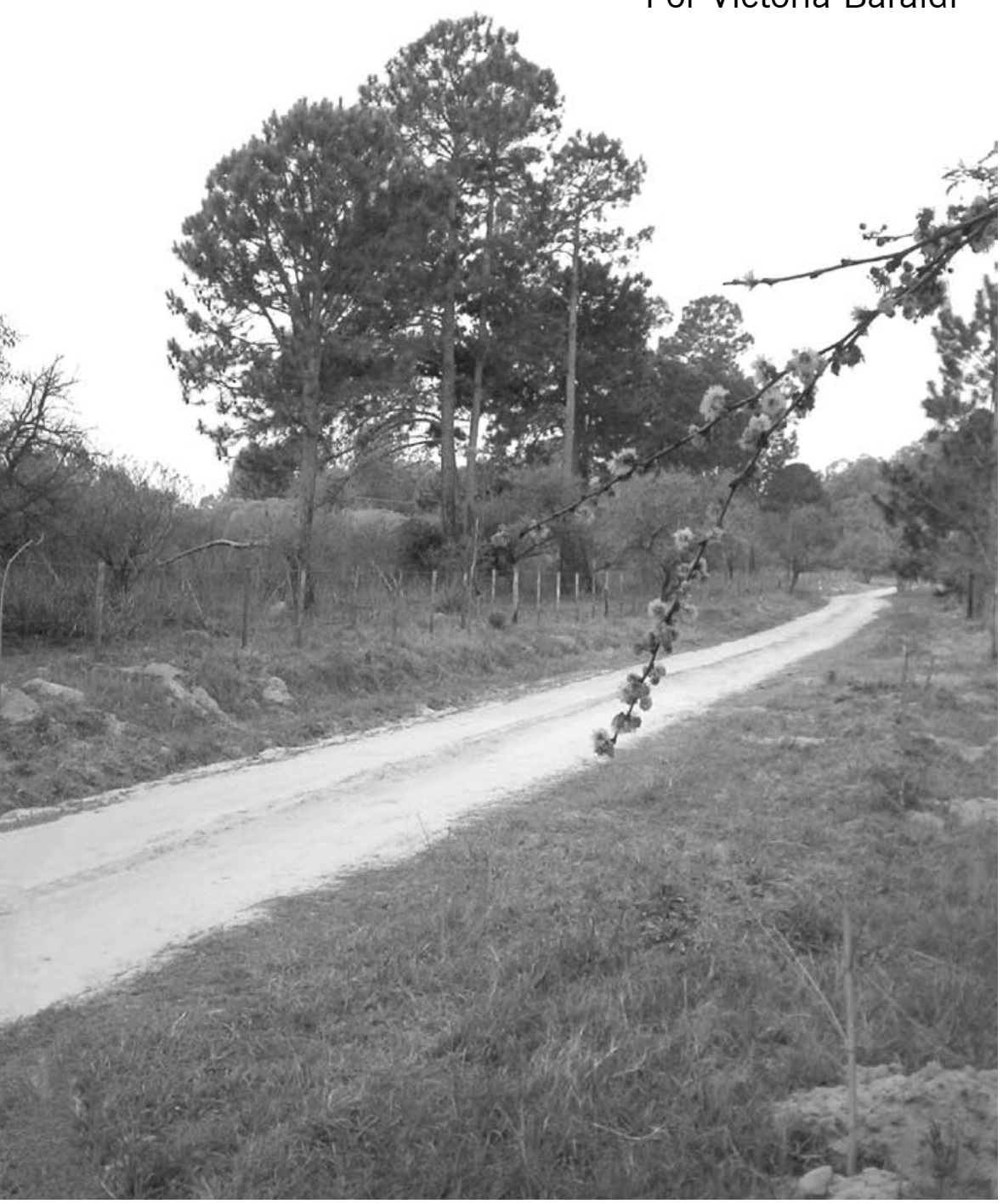

(1) Docente Ordinaria de Didáctica Gral. de la FHUC -UNL-y de Didáctica II de la UNER. E-mail: vbaraldi@fhuc.unl.edu.ar 
Hablar de educación en la Provincia de Santa Fe, haber sido alumno o profesor de la Escuela Almirante Brown, o de las instituciones de formación docente en la región, conlleva la evocación y el recuerdo del Profesor Ramón Félix Caropresi. Su nombre también es ineludible al rememorar las distintas etapas de la Facultad de Ciencias de la Educación de Entre Ríos. Para conocer desde sus propias palabras esa gestión y su trayectoria docente, es que compartimos a través de esta entrevista sus relatos y reflexiones.

Los Boletines Informativos de la Universidad Nacional del Litoral registran que el día 10 de marzo del año 1961 usted se hizo cargo del Decanato de la Facultad de Ciencias de la Educación. ¿Cómo llega a esta designación para asumir una misión tan importante?, icuál fue su estilo de trabajo?

El antecedente sería que me mandó a buscar a mi casa -esto sería para el anecdotario- el Rector de la Universidad del Litoral que era Josué Gollán, y yo estaba arriba del techo, levantando una cometa que le había construido a mi hijo. Venía de un traslape que sufrí en la Brown cuando me hicieron perder el concurso. No lo perdí yo porque quise, al concurso lo perdí porque fue una orden ministerial. ¿Por qué me echaron? No sé, más o menos me imagino... Me dijeron que mi exposición era "de alto vuelo universitario". De todos modos lo dimes y diretes me llevaron a enterarme que la parte gremial es la que incidió, la Asociación del Magisterio de aquel entonces...
Aquí Caropresi cuenta que primero lo felicitan por haber ganado el concurso, de "alto vuelo intelectual", y que al día siguiente le comunican que lo perdió. Con los años se enteró cuáles habían sido los procedimientos y los motivos de tan asombrosa actitud.

\section{Entonces, lo fue a buscar Josué Gollán...}

Sí, me fue a buscar y me ofrece la Facultad de Ciencias de la Educación de Paraná. Me explica un poco el asunto de la historia de la Facultad, me dice que Zanetti, el decano, había renunciado. El Profesor Zanetti fue el encargado de elaborar el plan de estudio, lo presentó y se fue.

\section{¿Por qué renuncia?}

La renuncia de Zanetti, no conozco los motivos. Era un hombre (...) más que nada un humanista. Leyendo esto ${ }^{(2)}$ te das cuenta de que es un hombre

(2) Se refiere al Plan de Estudios elaborado por Zanetti en 1960, que al momento de la entrevista lo tenía frente a él. 
que frecuentó las vetas del alto pensamiento, no sólo de la parte educativa, la parte didáctica.

Me hago cargo de la Facultad y ahí empiezo a preparar las condiciones para que todo esto pudiese llevarse a cabo. Y la verdad es que me costó un poco, porque el río, que hoy es un factor de unión a través del túnel, antes lo era de separación. Tal es así que por un lado era bueno, porque nos permitía movernos tranquilos, sin la necesidad de una permanente y constante supervisión de los cerebros electrónicos de las distintas Facultades. Porque no nos engañemos, yo tuve que luchar especialmente con todos los capitostes de las ciencias naturales, que estaban encaramados en las Facultades de Química y Bioquímica.

En cuanto había un aumento de presupuesto, nos llamaban a reunión y nos sacábamos los ojos (...) Porque se quedaban con todo. La vez que pude intervenir, lo hice con un poco de exigencia y de virulencia para empezar a sacar más presupuesto para la Facultad, y así fue.

\section{¿Se fue a vivir a Paraná?}

No. Viajaba en la lancha de la 6 y volvía en la lancha de las 7, 8 (...) Lo importante es que hubo necesidad de ir consolidando las distintas líneas que Zanetti marca en su plan de estudios, que son la línea psicológica por un lado y la línea sociológica por el otro. Ahí nacen, fui medio el padre, o el padre entero, de los dos Institutos de Investigación. El instituto de Psicopedagogía, y el instituto de Sociología de la Educación. Y ahí entonces viene la contratación de Tomás Vasconi, de Solidario Romero y de Mario Garo de Rosario.

Los institutos empiezan su tarea lentamente, pero con firmeza, y así comienzan a salir los primeros informes de avance.

\section{¿Hasta qué año dura su gestión como decano?}

Hasta el '66. Yo renuncio cuando se produce el golpe de Onganía en el '66. Nos reunimos todos los decanos en Rosario, para tomar una decisión conjunta, para formar un bloque decisivo que le demuestre al pueblo que estábamos todos en contra de la intervención federal a las Universidades. Pero yo no podía entregar la Facultad, sin antes esperar que viniera un nuevo decano. El nuevo fue Tealdi.

Pero antes de que llegue Tealdi, me pasaron cosas interesantes. Me visita el Jefe de la Policía Federal de Entre Ríos. Lo hago pasar, lo atiendo en compañía de mi Secretaria (...) Me dijo que quería visitarme porque necesitaba que yo le diera las fichas completas de los alumnos, profesores y no docentes comunistas y peronistas de la Facultad. Yo le dije: "Acá hay de todo. Tenemos una convivencia muy pacífica y muy rica que impide que yo pueda hacer de correveidile ahora. Yo no soy un alcahuete. No puedo decirle a Usted lo que me viene a pedir. $Y$ por favor, se retira, pero antes de que se retire quiero ofrecerle un plan de estudio para la tropa suya, porque les hace falta".

\section{Y... ise lo aceptó?}

iNo! iNo! Y me dijo: "Si usted se niega a contestar a mis requerimientos, no va a faltar oportunidad para que los Servicios de Seguridad, lo molesten y lo inviten a...". "Cuando usted quiera" -le dije.

Se fue. Eso fue en mayo o junio del '66. Pero resulta 
que me agarran de vuelta. Yo llegué a la Facultad como profesor. En el '70 gané un concurso con el Decanato de Tealdi, me podrían haber liquidado, pero no, al contrario. Era un jurado de alto nivel, impecable. A ese concurso lo gané. Pero esa vez no me dejaron entrar en la Facultad. Me echaron de todos lados. Porque inclusive me echaron sin indemnizarme. Yo estaba por concurso en todas las cátedras, tanto en la Facultad como en el Instituto del Magisterio.

Vos me preguntabas cómo llegué al Decanato. Así como integré la comisión Asesora para la Escuela Brown, con Ana María Caffaratti, Delia Travadelo, Gabriela Ulloa de Vazeilies, Rolando Ereñú, aparte de eso yo integraba una especie de (...) eso que hierve y que no podés caratularlo como algo sistemáticamente institucionalizado (...) pero que existe. Nos encontrábamos con Ana María Caffaratti, con Delia Travadelo, con gente así y coincidíamos pedagógica y políticamente en una cantidad de situaciones, aunque no en todas, pero bueno...

\section{Era un grupo muy...}

Era un grupo con levadura. Cosa que nos hizo muy bien a todos. Ana María Caffaratti, llevó adelante el Instituto del Profesorado Básico, que luego se transformó en Escuela Universitaria del Profesorado.

Con respecto a ese grupo "con levadura" (...) me gustaría que nos cuente cómo fue el proceso de su formación como docente. ¿Cómo se inician?, iquiénes fueron sus maestros? Yo tengo que agradecer. Soy un privilegiado en todo sentido. No es que haya sido ayudado. Sí, fui ayudado. Fui ayudado como toda persona que cumple (...) Soy un privilegiado un día me vinieron a buscar...

\section{¿Dónde estudió?}

¿Yo?, en la escuela Normal Nacional.

Me vinieron a buscar para ir a trabajar en la cárcel. "No importa que no esté recibido" -me dijeron.

\section{¿Quién le dijo?}

Liberto Cordero de Rivera (...) Muy católico él. Y así empiezo a trabajar antes de recibirme, en la cárcel. Antes repartía boletines, porque yo ayudaba a mis padres, controlaba a la gente que entraba al cine, porque antes el impuesto escolar se pagaba al día siguiente de hecho el espectáculo...

\section{¿De qué época estamos hablando?}

Del '43 al '50.

\section{¿Cuándo se recibe de maestro?}

En el '46. Me recibí bien, en tiempo y forma. Dejé de fiscalizar impuestos para ir a la cárcel. Primero empecé a trabajar como reemplazante y luego como interino. Finalmente como titular. Trabajé hasta el '58. Del '45 al '58. Esto hace que tenga unos 60 años de servicio.

La cárcel me permitió a mí entrar en contacto con una realidad totalmente nueva. Fue una especie de (...) ¿cómo puedo decir? (...) cuando vos te asombrás frente a una cosa así. Me permitió comenzar a comprender al otro, mucho antes de que tal vez 
otras personas lo empezaran a hacer. Y como había una base católica de mis directores (...) Eso me permitía moverme tranquilo para estar con ellos, conversar con ellos. No había represión pedagógica de ningún tipo, como Makarenko. Makarenko empezó aprendiendo y terminó aprendiendo. A mí también me pasó lo mismo. Ahora, estar en contacto con los presos, me hizo hablar con jueces, con abogados, una cantidad de cosas que me dieron un dominio, me permitieron hacer un buen gobernante maestro. Gobernar mis impulsos y mi comportamiento para lograr mejores resultados en la gestión educativa. Nosotros dábamos clases por ejemplo en la capilla. Estudios primarios. Por ahí agarraban y se peleaban entre dos, sacaban chuzas. Entonces había que ir a meterse (...) Yo iba, era grandote, tenía más fuerza que ahora. Había que separarlos. Eso sí, jamás denuncié a ninguno. Porque si vos los denunciabas los ponían en un calabozo (...) Y eso a mí me permitió conquistar un lugar de especial consideración. Tan es así que tengo un ejemplo: un día yo estaba muy enojado con alguien del Consejo de Educación, entonces me vio uno de los presos y me dijo:

“-¿Qué le pasa maestro?

-Y no... ando...

—¿Quién es?

— ¿Por qué querés saber quién es?

—Yo salgo la semana que viene. Yo lo arreglo..."

Esa es una. Después tuve dos estafadores (...) Uno grande que estafó al Cine Colón en 40.000 pesos de aquellos años. La cuestión es que los dos trabajaban en la escuela, colaboraban en la biblioteca, y eso (...) Uno de ellos sale y aparece en casa. Mi hijo mayor era chiquito, tenía un año. Vivíamos en calle de tierra.
Me dice: "Hola maestro, ¿cómo le va?"

Era un preso que había salido en libertad y no tenía para viajar a Buenos Aires. "Necesito 50 pesos". Yo tenía un sueldo de 325 mensual y andaba más o menos con 45,50.

“-Mirá te doy todo lo que tengo, pero si vos me lo mandás de vuelta.

-Quédese tranquilo maestro, que yo se lo devuelvo."

Le di los 50 pesos. Cenó con nosotros. Se fue a Buenos Aires, y desde allí a vuelta de correo, me los mandó con bono postal, que era más caro.

El otro, el que estafó grande al Cine Colón, y le metió la mula que venía un cantante francés (...) Y una vez que sale en libertad me pide que le saque un crédito de 1.000 pesos.

"Necesito ropa, zapatos, camisa, no tengo nada (...)", me dice.

Ahí la cosa se complicaba porque un crédito de 1000 pesos!! Me pagó religiosamente (...) Es decir que dos estafadores profesionales, cumplen conmigo. iCómo no querés que yo confiara en la gente y en mi interlocutor! Eso me fue enseñando muchas otras cosas. Después me sirvieron en la Facultad. Trabajé en la cárcel hasta el '58, porque me designaron como profesor, dejé.

Esta experiencia que yo tuve fue suficiente para darme dotes de gobierno. Así le llamábamos en pedagogía. Las dotes de gobierno que necesita todo docente, para poder comprender, animar, asistir y ser un compañero de camino de los alumnos que uno tiene. Que no es fácil ser compañero de camino. No es fácil. Es más sencillo aplazar, o hacer a un lado el problema y no es sencillo. Yo de todos modos agradezco ese privilegio que tuve 
de conocer a tanta gente en la cárcel. A tal punto que estuve por adoptar una criatura que él no la podía tener, tenía los papeles pero luego salió en libertad. Estábamos de acuerdo con mi señora, por supuesto. Era una nena.

\section{¿Ya tenían hijos?}

Sí, ya teníamos dos.

Así se fue armando lo que te digo de la levadura. Sale un poco del sentido que uno tenía, no tanto metafísico religioso, sino más vale personalístico, fruto de la observación, del querer, del saber y del hacer. Pienso que eso me ayudó mucho, ¿no?

\section{Un aprendizaje más desde la vida que un aprendizaje académico.}

Eso me permitió en la Facultad.... La gente me decía: "iUsted está loco!" Contratar profesores no era sencillo. iContratar profesores de alemán, de inglés, de francés! Hicimos un poco de concurso, para saber que no entraba cualquiera. $Y$ efectivamente, fueron todos muy buenos.
Aquí Caropresi comienza a recordar algunos nombres Madame Darriuex, Guillisasti, Sergio Bagú ${ }^{(3)}$...

Yo entré en el '61 y terminé en el '66. Estuve cinco años como Decano.

Era una época de ebullición en la educación. En la universidad hay un fuerte impulso por las ediciones, creación de los comedores escolares, los proyectos de la ciudad universitaria. Pero también había luchas por mejor presupuesto universitario.

Desde Frondizi '58, '59 y '60, hasta IIlia '62, '63 y '64. En aquellos años pasaban cosas asombrosas con el presupuesto universitario. El parlamento votaba el presupuesto, y estábamos todos contemplados en el presupuesto. Pero íbamos más allá. En marzo se anunciaba el primer refuerzo presupuestario, y para septiembre u octubre el segundo refuerzo presupuestario para las Universidades Nacionales de Argentina. Lo que nos permitió pelearnos a muerte con los otros decanos de las otras Facultades. La gente de Química, la de Bioquímica y toda la gente de Ciencias Naturales y
(3) En el marco del proyecto de investigación que se está desarrollando sobre la Historia de la Facultad en Ciencias de la Educación, dirigida por el Prof. Edgardo Ossanna, a raíz del relevamiento realizado por la Prof. Marisa López se registró la presencia durante este período de los siguientes profesores: Dr. Juan Eugenio Zanetti, Sergio Bagú, José
Carlos Chiaramonte, Beatriz Bosch, Ana María Caffaratti, Sonia Baraldi de Marsal, Raúl Lorenzo Posse, Renee Trettel de Fabián, Gustavo Cirigliano, Tomás y Rubén Vasconi, Delia Travadelo, María Saleme de Bournichón, David Viñas, Dra,. Angela Romera Vera, Luis Vinacua, Silvia Sigal, Mario Garo, Solidario Romero, Diomira
Carrara, Angela López Dabat de Aldaz; Olga Cossettini, Inés M. de Hischson, Celia Ortiz de Montoya, Carlos Tealdi, Matilde Kejner, Juan Carlos Calvoso, Raúl Echauri, Mario López Dabat, entre otros. 
Ciencias Exactas, especialmente los matemáticos. ¿Sabés lo que era tener dos o tres presupuestos? Había dinero y lo invertían bien.

\section{Debe de ser el único periodo en que esto ocurrió, ino?}

Claro. '58, '59, '60 y '61, Fueron años claves del desarrollo universitario, científico y pedagógico. Illia fue uno de los presidentes, de acuerdo a estudios realizados, parece que el único gobierno del siglo XX que tuvo todas las de la ley, y le mandaron 10 mil tortugas para sacarlo del poder. iY lo sacaron a empujones! Lo que se hizo en educación fue muy importante. Y no se hizo más porque surgen escollos cuando hay mucha resistencia de parte de determinados grupos del establishment que se oponen al avance y al progreso de los pueblos.

Aquel momento era un momento de expansión educativa y un período clave para la vida universitaria en particular ${ }^{(4)}$. Sí. En la facultad en ese período se concretaron muchas cosas. Por un lado el Instituto de Idiomas, y por otra parte, todo lo que fue la propuesta editorial. Teníamos Los cuadernos de difusión, con 3.000 ejemplares por número, Los Manuales con 4.000 ejemplares, Los libros, con temas nuevos de educación, y los Informes preliminares de investigaciones. Cuando vinieron los militares había más de 1.500 informes preliminares de in- vestigación. Y después los señores lo mandaron a los sótanos de los Alpes.

\section{¿Existen esos informes?}

No. Estuvieron bajo agua, los quemaron...

¿Eran informes producidos en la Facultad 0 invitaban también a otros profesores a participar? ¿Por qué tanta cantidad?

Los alumnos participaban activamente en la confección de los informes preliminares. Había alumnos, ayudantes, jefe de trabajos prácticos, egresados. Una experiencia única se hizo. El que tiene que tener buena memoria es Solidario (...) Se organizó la Primera Reunión Nacional de Jefes de equipos de Investigación Pedagógica de las Universidades Nacionales Argentinas. También se creó el Departamento de Pedagogía para aglutinar todo el esfuerzo pedagógico-didáctico de la Facultad, que estuvo a cargo de la Dra. Montoya.

¿Cuál era el espíritu básico para la formación de los alumnos, en qué eje se hacía más hincapié? ¿Con qué ideas se los pretendía formar?

Bueno era un avance hacia la democracia y hacia la participación plural.

No todos los colegas estaban de acuerdo-psicólogos
(4) Hay que recordar que por ese entonces, regían en la Universidad los concursos docentes, la periodicidad de cátedra, el cogobierno, un nuevo impulso a la extensión y a la investigación. Esos fueron los principales flancos que atacaron luego, los golpes del '66 y del '76. 
incluidos- por ejemplo, con la facilitación. Para mí la facilitación siempre fue un hecho importante que permitía manejar desde la cátedra en forma sagaz y al mismo tiempo rendidora, porque es importante que la participación se dé en forma total y absoluta. Por ejemplo, en la participación de las notas. Hay profesores que se niegan. Tengo ejemplos feos.

Parece que el autoritarismo no desaparece del todo. (...) No hay que andar mucho para darse cuenta de que hay docentes autoritarios (...) autócratas. Para tratar de desarrollar la idea de la facilitación es que hay que poner en tela de juicio el autoritarismo.

\section{¿Alcanza a implementar el plan de Estudios de Zanetti?}

Sí. En donde no logré, creo que lo logró Marta ${ }^{(5)}$, fue el hecho de organizar una buena cosmovisión que caracterizara tanto a alumnos, como a docentes, como a egresados... Un poco la idea de la universidad, de la vieja reforma universitaria de Córdoba. Para tratar de que el plan de estudio fuera algo distinto o por lo menos mejorara. Yo no alcancé a hacerlo, me hubiera gustado. Marta llegó más lejos, avanzó bastante.

Cuando uno habla de educación en Santa Fe, siempre aparece su nombre ya sea por los vínculos docente-alumno, por su compromiso, por su vehemencia, por los proyectos innovadores. Si usted mira hacia atrás, icuáles fueron - para usted- los momentos más entrañables de su práctica docente? En primer lugar la cárcel de Encausados, en segundo lugar, la Escuela Brown. En tercer lugar...
Aquí Caropresi comienza a recordar también a la Escuela Normal San Martín, pero se detiene en lo que fue la experiencia de la escuela Brown. Se refiere a la modificación de la organización horaria, de los talleres, del coro, de la vehemencia con que actuaba el grupo de profesores.

\section{¿Quién era el director cuando comienza a funcionar?}

Carnevalli pensó a Brown como una escuela para que recibiera todos los rebotados de otras escuelas. Fue muy importante esa experiencia. Yo me hago cargo de la escuela y me tomo la atribución de aplicar, de lo que pude aplicar del plan de estudio de Brown. Por ejemplo la comida para doscientos cincuenta comensales gratis. El coro, los talleres, otra organización horaria. Una experiencia fue la recolección de alimentos y abrigos para mandar a Chile. Fue muy importante esa experiencia para los alumnos. Estuvieron dos días completos, dividieron la ciudad en manzanas, cada grupo se ocupó de dos manzanas y mandamos un avión con treinta toneladas de cosas a Chile. Todo desde la escuela.

Los proyectos que de alguna manera podemos englobar en los proyectos de escuela nueva, tienen una mayor vinculación con la comunidad, ino?

Sí, sí. Se me ocurre que hubo interferencias que fueron las que impidieron que el plan de estudios de Brown se aplicara íntegramente. Hubo interferencias gremiales que son lo que a mí más me dolió. El gremio estaba en contra de que en el octavo año, egresados del Brown, pasaban a hacerse cargo de

(5) Se refiere a Martha

Benedetto de Albornoz. 
un grado, pero titular, y se preveía la realización de la práctica docente con medio sueldo. No era un egresado, era un conjunto, que tomaban una escuela para poder ir preparando el ambiente de todos los grados, experimentalmente hablando. $\mathrm{Y}$ eso les chocó mucho a los viejos gremialistas (...) Yo me siento protagonista de Brown. Cuándo logramos itres mecheros para cocinar para 250 alumnos! no era sencillo. Y eso se logró. Lo hacíamos en las aulas. Juntaban las mesas y se armaba el gran comedor. Con experiencia de todo tipo. Aprendizaje inclusive para comer, que muchos de ellos no tenían...

Caropresi, cuando yo le pregunté por los referentes usted mencionó la experiencia de la cárcel donde usted aprendió mucho, ¿qué otros referentes tuvo, de que otras situaciones aprendió?

La relación maestro-alumno, grupo de alumnosdocente. Otro elemento que podría aportar (...) y bueno, habría que pensar qué beneficios me reportaría, por ejemplo, el hecho de que en el año 71 me valió mucho como experiencia el viaje que hice a Chile, que me mandó la UNESCO, por invitación de uno de los jefes de la UNESCO de París, Ángel Diego Márquez. Fuimos a prepararle la agenda anotada de los Ministros de Educación de toda América, inclusive Estados Unidos. (...)

Yahí vienen nuevamente las anécdotas, las de quien, portador de una cosmovisión humanista, sigue constantemente aprendiendo y enseñando.

Gracias maestro. 